\title{
Modal Analysis on Cab Body-in-white of Heavy Commercial Vehicle
}

\author{
Guoyu Feng ${ }^{1,2, a}$, Wenku Shi ${ }^{1, b}$, Guangming Wu ${ }^{1, c}$, Wei Yang ${ }^{1, d}$
}

${ }^{1}$ State Key Laboratory of Automobile Dynamic Simulation, Jilin University, Changchun Jilin, China

${ }^{2}$ Department of Aviation Theory, Aviation University of Air Force, Changchun Jilin, China

awsry1819@sina.com, bshiwk@jlu.edu.cn, ${ }^{\mathrm{c}}$ wugm@jlu.edu.cn, ${ }^{\mathrm{d}} 356661132 @ 163 . c o m$

Keywords: Heavy commercial vehicle, Cab white body, Finite element method, Modal analysis

\begin{abstract}
The finite element model for the cab body-in-white (BIW) of heavy commercial vehicle is setup, and based on which a modal analysis is performed. In order to verify the accuracy of the model, using multiple input multiple output methods on body structure modal test, using modal analysis technique to identify the inherent frequency and vibration type. Access to the cab modal distribution, in order to improve the structure of the weak areas to enhance the overall performance of structure, proposed amendments.
\end{abstract}

\section{Introduction}

Heavy commercial vehicles are widely used in the engineering field, due to the continuous long running time road condition is poor, the overload situation seriously, vibration, to ensure the driving safety and ride comfort has put forward higher requirements. The effect of occupant comfort factors, the cab structure vibration is one of the main factors [1]. Cab vibration in the steering system, the seat panel and the body panel feel, touch, vibration and noise will cause fatigue driving. In order to reduce the vibration and noise in the cab, using modal analysis technique to identify the inherent frequency and vibration type, in order to understand the structure of the weak area and main source excitation frequency, gain cab modal distribution, evaluation of the dynamic characteristics of the structure of [2]. In order to improve the structure of the weak areas to enhance the overall performance provide evidence.

\section{Modal analysis theory}

Modal analysis theory mainly includes real modal theory and complex mode theory. Real modal theory is applied to the undamped modal analysis, the cab damping modal analysis is the need using the complex modal theory $[3,4]$.

Due to the complex structure with an infinite number of degrees of freedom, to facilitate the analysis of the discrete $\mathrm{N}$ a limited degree of freedom linear vibration system, application of the method of state space analysis. System forced vibration differential equations:

$$
[M]\{\ddot{x}\}+[C]\{\dot{x}\}+[K]\{x\}=\{f(t)\}
$$

Type, ${ }^{[M]}$ for the mass matrix, $[C]$ for the damping matrix, ${ }^{[K]}$ for the stiffness matrix for the system, $\{x\}$ for the generalized displacement matrix, $\{f(t)\}$ for exciting force vector. Solution of eigenvalues and eigenvectors, namely the modal frequencies and the corresponding formation. In practical situations, generally on the actual response contribute mode, called effective modal. Effective modal is usually higher than the theoretical calculation mode of small. In order to avoid excessive adverse effects, such as noise mode and may make the equations of morbid, usually adopts the main decomposition technique, the matrix rank reduction.

In order to check the accuracy of finite element calculation model, need to do a modal test verification, of modal correlation analysis [5-7]. For having $n$ degrees of freedom linear system, the 
one order modal and experimental modal shapes are respectively defined as n-dimensional real linear space $R^{n}$ points $X=\left\{x_{1}, x_{2}, \cdots, x_{n}\right\}$ and $Y=\left\{y_{1}, y_{2}, \cdots, y_{n}\right\}$, the inner product is

$$
\langle X, Y\rangle=\sum_{k=1}^{n} x_{k} y_{k}
$$

Product related degree is

$$
C_{p}(X, Y)=\frac{|\langle X, Y\rangle|}{\sqrt{\langle X, X\rangle\langle Y, Y\rangle}}
$$

Apparently in $C_{p}(X, Y) \in(0,1)$, its value is to $1, X$ and $Y$ correlation is higher, the calculation model and experimental models in this mode the kinetic characteristics of the closer.

\section{Cab BIW modal finite element analysis}

Commercial vehicle cab is mainly composed of white body, door, and the body interior and exterior decoration. While the white body is the main part of the cab, determines the cab structure characteristics, so the vehicle BIW modal analysis, obtained cab modal parameters. The basic vehicle body in white is made of sheet metal parts by welding, thickness of most at around $1 \mathrm{~mm}$, the maximum thickness is less than $3 \mathrm{~mm}$. Establishment of BIW finite element model first need to establish good 3D model through.igs format into HyperMesh grid. In order to improve the quality of mesh, mesh and computation efficiency, while the accuracy is guaranteed conditions need to be simplified model. Body in white, such as technological hole in the small lug, flanging, opening size smaller structures, the part of the component stiffness is very small, can be neglected in modeling. On the main body through the four node shell element grid, the irregular shape part mainly uses the quadrilateral and triangular partition. Grid cell size is $10 \mathrm{~mm}$, spot welding simulation precision of the model is very important, the use of high precision umbrella model to simulate the spot $[8,9]$, establishing the finite element model of body in white with 235032 unit, wherein the quadrilateral element 227147.

Table 1 The results of calculation mode

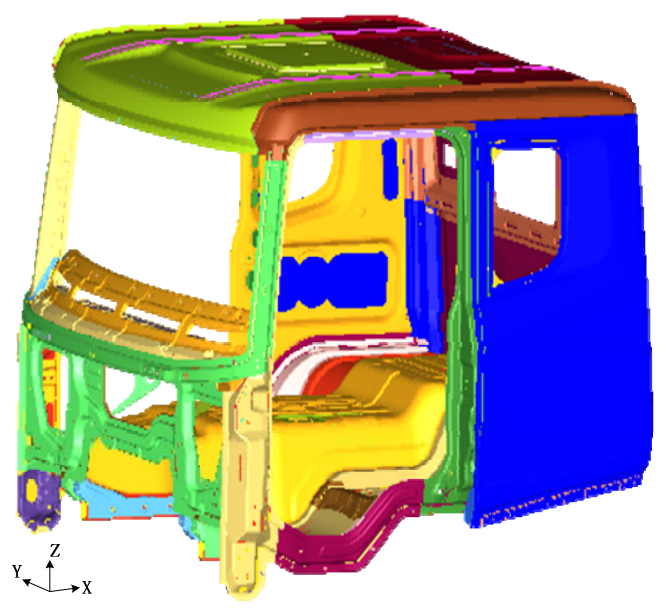

\begin{tabular}{|c|c|c|}
\hline $\begin{array}{c}\text { Order } \\
\text { number }\end{array}$ & $\mathrm{f} / \mathrm{Hz}$ & Vibration type description \\
\hline 1 & 22.304 & $\begin{array}{l}\text { Overall around } \mathrm{X} \text { axis first order } \\
\text { torsional }\end{array}$ \\
\hline 2 & 23.951 & $\begin{array}{l}\text { Top cover first middle order } \\
\text { bending }\end{array}$ \\
\hline 3 & 26.882 & $\begin{array}{l}\text { Top cover, rear wall, lateral } \\
\text { vibration }\end{array}$ \\
\hline 4 & 29.965 & $\begin{array}{l}\text { Top cover second order } \\
\text { bending }\end{array}$ \\
\hline 5 & 34.493 & After round first vibration \\
\hline 6 & 37. & rder bending \\
\hline 7 & 38.556 & $\begin{array}{l}\text { Top cover, front window upper } \\
\text { coupling vibration }\end{array}$ \\
\hline 8 & 40 & $\begin{array}{l}\text { Top cover, after perinatal } \\
\text { coupled vibration }\end{array}$ \\
\hline
\end{tabular}

Fig.1 Cab BIW finite element model

Using ABAQUS software to BIW finite element model of the free modal analysis calculation, in which the welding part connected by Tie simulation, bolt connection with beam element to simulate. Modal part is obtained by calculating the results in Table 1, the first two order modal images shown in figure2. 


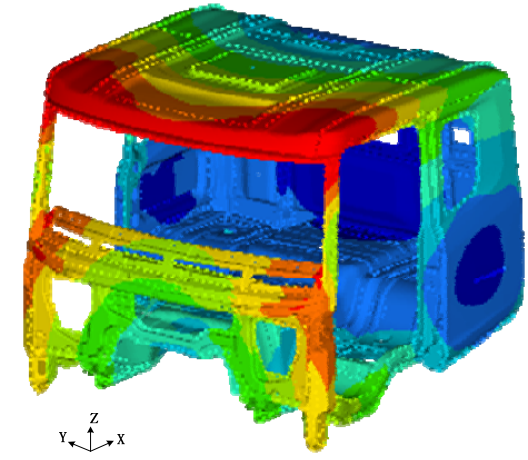

(a) Overall the first-order torsional vibration model

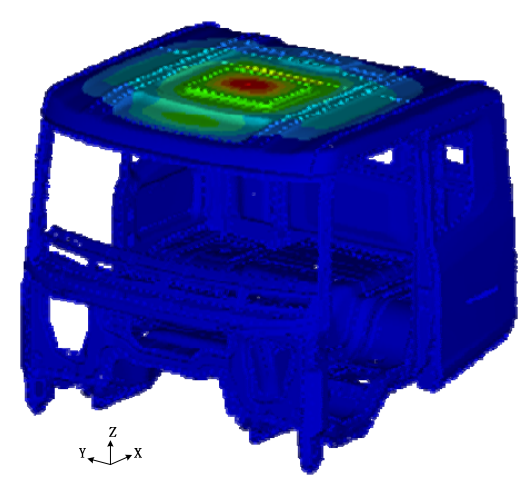

(b) Second order bending vibration model

Fig.2 BIW modal vibration shape

The simulation results show that the cab 1order torsional frequency lowest, followed by the cab ceiling1order bending and after perinatal1first bending mode frequency. This is mainly due to the two part of the larger and smaller thickness. The floor and the front vibration frequency slightly higher, mainly due to the floor portion while the area is large, but the thickness than the other two part of large and reinforcing structure; the circumference position of irregular structure, a relatively small area, so that the two parts of the modal frequency slightly higher. The overall local mode is more abundant, modal distribution exhibits a front weak, the strong weak side top strong trend. Especially the ceiling was larger in amplitude, deformation is obvious, the frequency distribution is broad, need to strengthen the here.

\section{Cab BIW modal test}

In order to verify the results of calculation mode, on the cab body-in-white modal test, uses multi-reference least-squares complex frequency-domain (LSCF) method for the identification of modal parameters. Test of modal test equipment are connected as shown in figure 3.

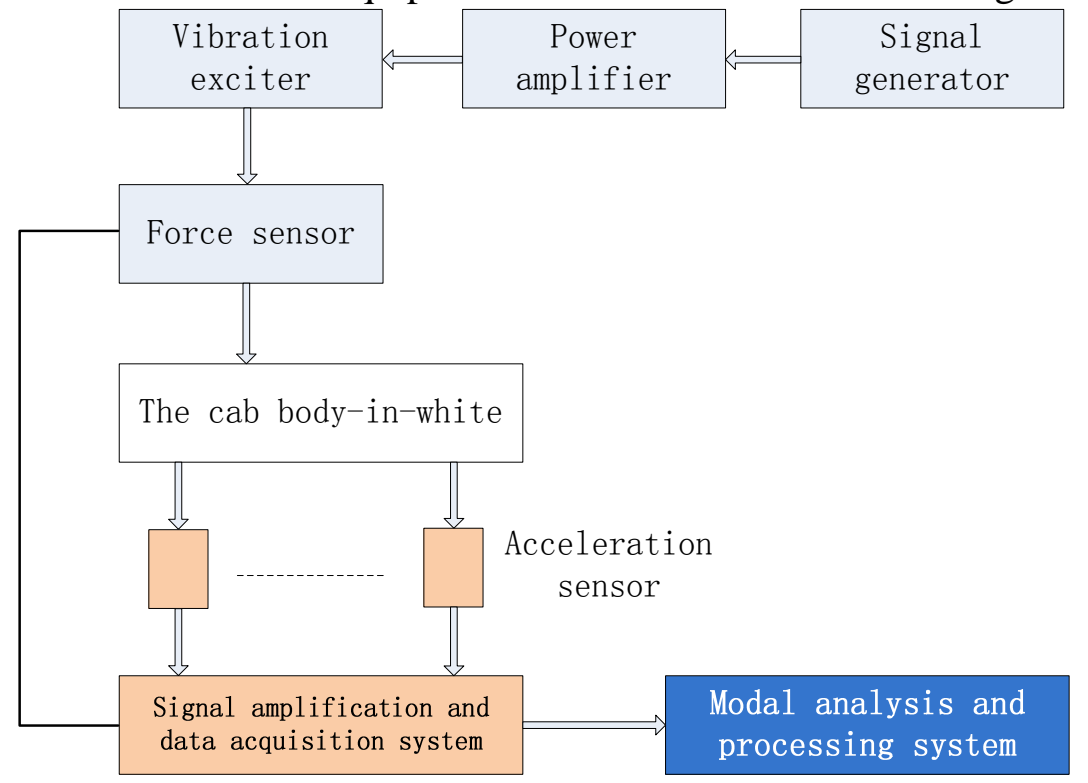

Fig.3 Cab BIW modal test system

Cab uses four rope hoisting, using multiple input multiple output methods on body structure modal test. The use of 2electromagnetic vibration exciter excitation of white bodywork. In order to be able to drive a car body in white of the direction of the modal, a vibrator mounted on the cab left anterior position, the longitudinal vertical plane and horizontal plane obliquely upward and inward at a 45 degree angle drive. Another vibrator mounted on the cab right posterior position, horizontal vertical vibration direction and the horizontal plane form an angle of 45 degrees, the body in white as shown in figure 4. 
Vibration response point arrangement in relation to the modal testing result accuracy. According to the results of finite element analysis of vibration pattern is more obvious points combined with practical experience, identify the cab sensor placement. Test point arrangement in response to most of the uniform, for a small group of modal vibration dense point due to increase in response to the point number. Cab pick-up point number is 428, in which the excitation point to the 2 point, local mode408, mode18 points overall, as shown in figure 5.

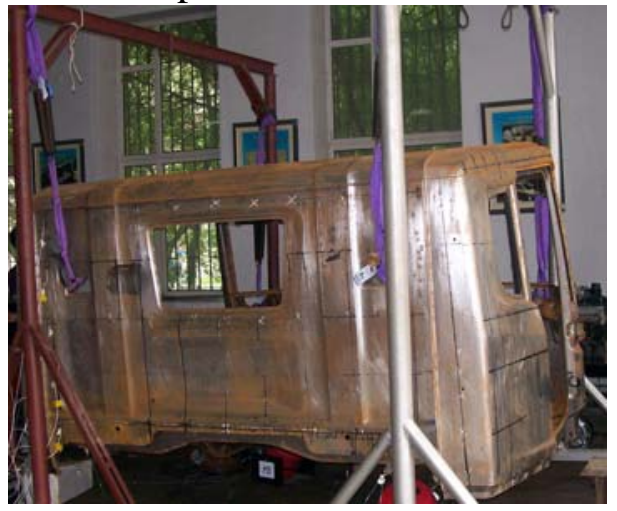

Fig.4 Exciter arrangement

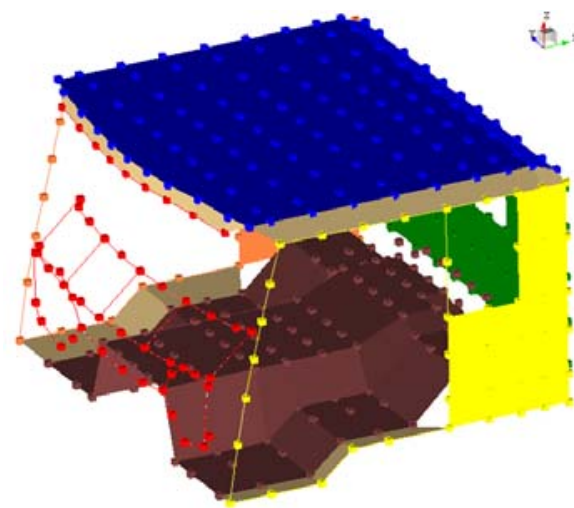

Fig.5 Response point distribution

Using random burst signal BIW incentive, incentive in the frequency range $0 \sim 100 \mathrm{~Hz}$. Using Haning windows to reduce leakage error. Test408response points are divided into 15 groups for each measurement, test of vibration exciter on white body drive25, test during surveillance of coherence function, verify the frequency response function is effective, and the data were averaged to reduce the random error of measurement processing. To deal with the experimental data, the main test mode as shown in Table 2, the first two order modes as shown in figure 6.

Table 2 Results of experimental mode

\begin{tabular}{|c|l|c|l|}
\hline $\begin{array}{c}\text { Order } \\
\text { number }\end{array}$ & $f / \mathrm{Hz}$ & $\begin{array}{c}\text { Damping } \\
\text { ratio }\end{array}$ & \multicolumn{1}{c|}{ Vibration type description } \\
\hline 1 & 23.3835 & $0.23 \%$ & Overall around X axis first order torsional \\
\hline 2 & 24.6132 & $0.04 \%$ & Top cover first order bending \\
\hline 3 & 27.9627 & $0.15 \%$ & Top cover, side, front coupling vibration \\
\hline 4 & 30.4706 & $0.30 \%$ & After perinatal first order bending \\
\hline 6 & 38.9476 & $1.20 \%$ & Ceiling second order bending \\
\hline 8 & 45.9525 & $0.22 \%$ & Top cover, after perinatal coupled vibration \\
\hline
\end{tabular}
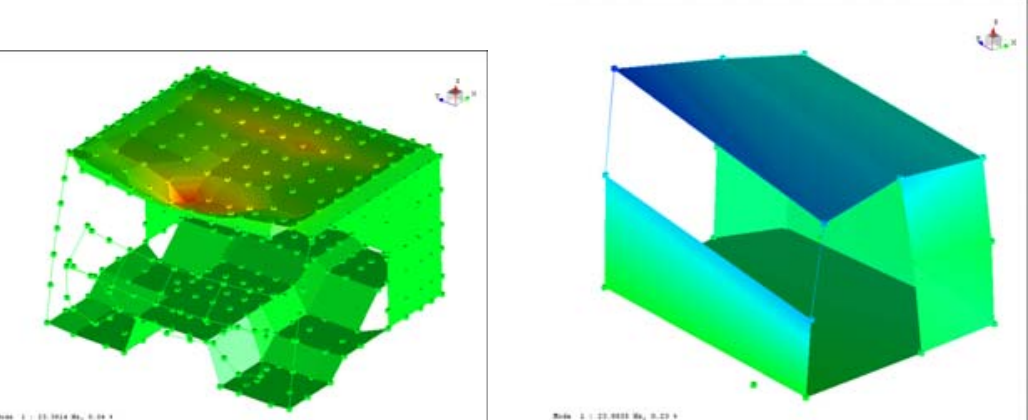

(a) Whole first order torsional vibration mode (b) Top cover first order bending

Fig.6 Part test mode

Modal test results indicate that:

- From the frequency range of $0-100 \mathrm{~Hz}$, cab whole mode frequency distribution is reasonable. The cab the first frequency is $23.88 \mathrm{~Hz}$, meet minimum requirements.

- Cab roof panel, left and right, rear panel, floor, ceiling, cowl panel, instrument panel edge, first order frequency, are about $23 \mathrm{~Hz}$, very close to easily cause the Cab Acoustics cavity resonance.

- The engine idle speed650RPM, corresponding to the third order vibration frequency is 32.5Hz. Through the experiment, floor, ceiling and side panel in the frequency near the elastic modes. 
The simulation results and test results, mainly in the test mode in simulation results are corresponding, the simulation results and experimental results in vibration and modal frequency is quite close, proves the accuracy of this finite element model. However, due to the experimental arrangement of measured points than the finite element model of node a lot less, leading some to calculate modal in the experiment did not occur.

\section{Conclusion}

In order to obtain a commercial car body-in-white dynamic characteristic, has carried on the theoretical calculation and the experimental modal analysis, in order to further on the body to carry out the sensitivity analysis and structure dynamic modification laid the foundation. According to the analysis of the simulation and test results, the cab local existence not ideal structure, in order to improve the overall performance, put forward the following suggestions for improvement.

- Roof isolation type is rich, the stiffness is obviously insufficient, in most modes are the part of the local vibration, especially with the louver openings reserved part of strengthening, can be optimized through the ceiling beam structure, increase the thickness of plate and optimize the roof reinforcement shape and position, in order to improve the stiffness.

- In front of floor vibration is also rich, shown here stiffness discontinuous easily cause the safe hidden trouble, need to strengthen.

\section{Reference}

[1] He Yusheng. Vehicle Noise Control [M]. Beijing: Mechanical Industry Press,1995:105-106.

[2] Hu Yumei. Vibration Modal Analysis Technology [M]. Chongqing: Chongqing University press,2006

[3] Fang Yuanqiao, Chen Anning, Dong Weiping. The Finite Element Method the Principle and Numerical Method M]. Beijing: National Defense Industry Press,1993

[4] The horse Tianfei, Wang Dengfeng, Liu Wenping. A Study on the Modal Analysis and Test on the Cab Body-in-white of Heavy Commercial Vehicle(J).Automotive Engineering,2009(7):616-619.

[5] Santos FM, Temarel P, Soares CG. Modal Analysis of a Fast Patrol Boat Made of Composite Material [J]. Ocean Engineering, 2009, 36: 179-192.

[6] Wang Xucheng, Shao min. Finite Element Method Basic Theory and Numerical Method [M]. (2nd edition). Beijing: Tsinghua University press,1997

[7] Chen Zhiyong, history library, Shen Zhihong, et al. Modal Analysis for Body and Frame of a Light-type Bus [ J ]. Journal of vibration and shock,2010(10):244-245.

[8] LMS International Co. LMS Test. Lab-Structural Testing Software Rev 7B, Leuven, Belgium, 2007.

[9] Rudroju S,Gupta A,Yandamuri S.perational Modal Analysis of Aluminum Beams. Journal of the lest.2007.50(1):74-85. 